\title{
Reentry of elementary aged children following reunification from foster care
}

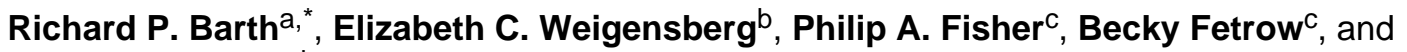 \\ Rebecca L. Green ${ }^{b}$ \\ a University of Maryland School of Social Work, 525 W. Redwood Street, Baltimore, MD 21201, \\ United States \\ b University of North Carolina School of Social Work, United States \\ c Oregon Social Learning Center, United States
}

\begin{abstract}
A recognized goal of family reunification programs is preventing the reentry of children into foster care. Using data from the National Survey of Child and Adolescent Well-Being, this study examined reentry for 273 children between the ages of 5 and 12 years. In multivariate models, reentry into foster care was associated with higher Child Behavior Checklist (CBCL) scores and higher numbers of children in the household when the child is living at home. Although these are not the only risk factors that should be considered in deciding whether to reunify a child, these characteristics appear to be high valence problems for families and their children who are reunified. Future research on reentry and on placement disruptions from foster care should routinely include information about the number of children in the family and behavior problems when endeavoring to explain caseload dynamics.
\end{abstract}

\section{Keywords}

Foster care; Reunification; Family size; Behavior problems; Longitudinal

\section{Introduction}

\begin{abstract}
When children enter out-of-home care, in the vast majority of instances, the service plan is to return them safely to their family. Yet, reunification fails in a substantial proportion of cases. This is an enduring concern to local, state, and federal child welfare administrators, who strive to keep the failure rate below strive to keep the failure rate as low as possible, especially since it is included as a performance measure in federal performance reviews. Reunification failures may result in reentry without abuse (e.g., when early warning signs of parental inadequacy are observed), abuse but no reentry into care, reentry into foster care (most often into another foster home), and greater likelihood of later placement instability and admission into group care.
\end{abstract}

\footnotetext{
(C) 2007 Elsevier Ltd. All rights reserved.

*Corresponding author. rbarth@ssw.umaryland.edu (R.P. Barth)..

6. Uncited references

Barth and Price, 2005

Simmel and Price, 2002

Slaght, 1993

U.S. Department of Health and Human Services, 2001
} 
Although rates of reentry vary widely, the available evidence has demonstrated that reentry to foster care after reunification is not a rare event. In one study of reunified families in Illinois (Goerge, 1990), one third of all children who were returned home during the 1980s, reentered foster care. Similar results were reported in a study of Texas reentry rates that showed that $37 \%$ of children who were reunified reentered foster care in Texas within 3.5 years (Terling, 1999). Wulczyn (2004) further reported that nearly $30 \%$ of children from 10 different states who were reunified between the early 1990s and early 2000 reentered care between those years. In the context of a randomized trial to evaluate a therapeutic foster care program, Fisher, Burraston, and Pears (2005) observed that over 50\% of children reunified or adopted following placement in regular foster care reentered care within 24 months.

Most studies of reentry into foster care have relied on administrative data collected during the routine operation of child welfare cases. This single-source reliance often means that models explaining reentry are not well-specified, and some findings are explainable by idiosyncratic administrative rules (e.g., by the coding of drug-exposed newborn cases as physical abuse in the state of Texas, as detailed in Terling, 1999).

Nonetheless, some findings from administrative data emerge with notable consistency. Courtney (1995), studied reunified foster children in California and found that six groups of children had faster rates of reentry than their comparison groups: (a) children with health problems; (b) children from families receiving Aid to Dependent Children; (c) children who spent three months or less in care; (d) children who were placed in nonrelative care; (e) children who had a greater number of placements during their first spell in care, (f) and African American children. Correlates of reentry in Terling's (1999) study included abuse type, prior child welfare services (CWS) history, parental competency, race, criminal history, substance abuse, and social support. Notably, in Terling's study, assessments of risk made by caseworkers were not found to be related to reentry.

A shorter duration in foster care appears more likely to be followed by a reentry into care. McDonald, Bryson, and Poertner (2006) recently studied the relationship between reunification and reentry rates for 33 Oklahoma counties occurring in 2002. Consistent with prior research (e.g., Wulczyn, Brunner, \& Goerge, 1999) McDonald et al. found a relationship between early reunification (less than 6 months spent in out-of-home care) and higher reentry rates; counties with the greatest number of cases in which reunification took place within the first 30 days reported lower reentry rates. Jonson-Reid (2003) found that children with a postreunification report of maltreatment or reentry were more likely to have been in care for a shorter time (i.e., less than three months in out of home care).

In general, foster care reentry research has included children of all ages. Although several studies have included age groups as predictors in their analysis, few studies have stratified their analyses by age. For example, Courtney (1995) found that children between 7 and 12 years had lower reentry rates than infants, but that this age group was indistinguishable from preschool children or adolescents. Wells and Guo (1999) disregarded the likelihood that there might be discontinuities in the relationship between age and reentry, and treated age as a continuous variable. They showed that the likelihood of reentry increases nearly $10 \%$ for each year of age at exit from foster care.

Reentry is also likely to be related to the number of prior foster placements. For example, Fisher et al. (2005) found that a positive association among foster children between number of prior placements and the likelihood of permanent placement failure. Children with multiple prior placements were much more likely to have difficulty achieving a lasting permanent placement. 
Research has consistently shown that a stronger developmental perspective is needed in child welfare research (Berrick, Needell, Barth, \& Jonson-Reid, 1998; Wulczyn, Barth, Yuan, Jones Harden, \& Landsverk, 2005) because the predictive factors for reentry in one age group may not be explanatory for another age group. Children of different ages enter care for different reasons (Barth, Wildfire, \& Green, 2006) and leave care at different rates (Wildfire, Barth, \& Green, 2007). The interrelationship of these factors is likely to contribute to reentry.

Only a few studies have looked in greater depth at reentry, by using more detailed case histories or observational/ interview data. These analyses have allowed for the inclusion of more varied predictors in the reentry models. For example, Frame, Berrick, and Brodkowski (2000) examined reunification and reentry among 98 infants in Alameda County California. Although their review of case records showed that maternal criminal history was a key predictor of reentry, they found no clear relationship to several other expected predictors such as type of maltreatment, parental visiting, gender, or time in out-of-home care.

Festinger's (1996) study of 210 children in New York and who were younger than 15 years at the time of entry into CWS is something of an exception. This study detailed measures of factors contributing to reentry, but obtained on a sample of children with a broad age range (with a median and mean age of about 6 years old). Of the 210 children sampled, only 27 experienced reentry during the 16 months after their return home. Festinger concluded that the reunifications that resulted in reentry were generally more problematic, and often took the form of limited parenting skills, poor social support, and a history of mental health problems and homelessness. Yet, none of these factors could be isolated as significantly different between reentry and nonreentry cases.

Fuller (2005) is among the few researchers who have examined reabuse following reunification (see also Jonson-Reid, 2003). Fuller examined the factors that appeared to predict short-term (i.e., within 60 days) maltreatment recurrence among 174 families with children returning home from their first stay in substitute care in Illinois. Seven variables were found to be positively associated with maltreatment recurrence: (a) younger child age; (b) poor parental mental health; (c) more prior placements; (d) initial placement type (kinship care); (e) total length of time in placement ( 3 or more years was a greater risk for recurrence); (f) more children in the home at reunification; and (g) children returning home to a single-parent household at the same time as one or more siblings. Although Fuller's study evaluated factors related to recurrence of maltreatment as opposed to subsequent reentry, it provides useful insight into factors placing children at risk of future CWS involvement postreunification.

Miller, Fisher, Fetrow, and Jordan (2006) studied the reunifications of children between 4 and 7 years of age through close observation and interviews with children who had recently returned home from foster care. Miller and colleagues found that parental substance abuse treatment (probably indicative of substance abuse problems), children in special education due to developmental delays, child's use of therapy for psychosocial maladjustment, overall parent skill, parental use of discipline, and the quality of neighborhood were all related to reentry.

Several factors have either not received much attention or the findings have been null. Prior studies have not identified gender as a major predictor of reentry. Both Fuller (2005) and Courtney (1995) tested gender and found no advantage to including it in their final models. Although Jonson-Reid (2003) found interactions between gender, age, and race that appeared important, it was not possible to replicate the prior findings in the samples stratified by age or in a smaller sample, as reported below. Fuller's (2005) study was the 
only recurrence or reentry study that examined the number of children living in the home as a risk factor for reentry. They found that children who were returned to homes in which four or more children were present were three times as likely to experience recurrence.

Only one study has tested the relationship between recent family experiences of domestic violence and reentry to foster care. English, Edleson, and Herrick (2005) noted that the child welfare worker rating at intake of the level of risk due to domestic violence had no significant relationship to rereferral in Washington State. This finding stands in sharp contrast to several studies that point to domestic violence as having a key role in reentry. For instance, Kohl, Edleson, English, and Barth (2005) found that domestic violence created a greater likelihood of entering foster care rather than being served at home; however, there are no published reports that have followed children in households with domestic violence to reunification or reentry. Marsh, Ryan, Choi, and Testa (2006) found that substance-involved families who make progress with co-occurring problems including domestic violence are more likely to experience reunification.

Cumulative family risk has also been inadequately studied as a contributor to reentry. Although family risk and child-level risk are different, it is reasonable to expect that these factors are related. Appleyard, Egeland, van Dulmen and Sroufe (2005) observed that cumulative risk for an individual child had a linear relationship to later behavior problems. Nair, Shuler, Black, Kettinger, and Harrington (2003) found that, among substance-abusing women, high numbers of parental stress factors were related to measured child abuse potential.

Many explanations are possible for the contradictory and tentative nature of existing findings. It is possible that there are very different dynamics within age groups that were not distinguished; unmeasured factors that would have, if included in all the models, provided more consistent results; and problems of power that reduced the chances of identifying significant factors.

The goals of the present study were to understand foster care reentry dynamics for a discrete group of children (elementary school age children) who have been reunified by considering factors that have routinely been tested in multivariate models (e.g., length of time in foster care before reunification), case characteristics rarely tested in reentry models (e.g., clinical level of behavior problems), as well as some additional factors which our clinical experience indicate may have an impact on outcomes (i.e., family size).

\section{Methods}

The present study used data collected for the National Survey of Child and Adolescent WellBeing (NSCAW) at baseline and through 36-months. NSCAW contains information on a nationally representative sample of children whose cases are investigated based on a plausible allegation of child abuse and neglect. Approximately $10 \%$ of these children enter out-of-home care immediately following such an investigation, and an additional 3\% enter out-of-home care in the subsequent year (DHHS, 2005). Based on the strong interaction between the age of children and the pattern of child welfare service use demonstrated in prior research (see Wulczyn et al., 2005), our analyses focused on a single age group: children between the ages of 5 to 12 years. This age group was selected based on the fact these ages that encompass the group of children most likely to have conduct problems and to have a history of physical abuse - two problems about which there is considerable intervention knowledge. In the 5 though 12 year-old age group of the NSCAW sample, 273 children entered out-of-home placement and were reunified at some point within the 36month data collection timeframe; however $58(16.28 \%)$ of these reunified children 
subsequently reentered out-of-home care within the 36-month period. The average time to reunification for those in out-of-home care was 12.64 ( $\mathrm{SE}=3.52)$ months. Among those who reunified, the average time to reentry to out-of-home care was 6.91 months $(\mathrm{SE}=1.50)$.

The present study examined the predictors of reentry into out-of-home care following reunification to the biological or extended family, with the intent of identifying case characteristics that might be amenable to an intervention using parent training.

\section{Measures}

Independent variables were divided into three categories, child-specific characteristics, familial risk factors, and agency or parent actions following the referral.

Child-specific factors included age in months, race/ethnicity, gender, primary type of abuse, and whether the child received special education services at baseline. The overall Child Behavior Checklist (CBCL) score at baseline was also used as a child-specific factor. Children with CBCL scores above 60 are classified as having clinical/borderline problem behaviors. The CBCL score at baseline has a range from 26 to 90 with a mean of 58.79 $(\mathrm{SE}=1.64)$.

Familial risk factors were captured in indicator variables as reported by the caregiver for prior child welfare involvement and a cumulative continuous score of family risk that came from the child welfare worker's completion of a comprehensive risk assessment checklist. The cumulative family risk score had a mean of.36 ( $\mathrm{SE}=.03$ ) and a range of .09 to .89 . It is a composite measure of family risk at baseline which includes such risk factors as active domestic violence, parental substance abuse, substance abuse of a secondary caregiver, abused as a child, poor parenting skills, and unable to pay for basic necessities. A higher score indicated greater risk.

The number of children living in the household when the child is placed in the home was also used as a familial risk variable, based on prior research on this factor's impact on placement instability (Chamberlain, Price, Reid, Landsverk, Fisher, \& Stoolmiller, 2006) and on clinical observation. The number of children living in the household was determined from caregiver reports of made at each wave of data collection. Typically, this count would have occurred following reunification because caregivers were not interviewed unless the child was in their care. When a discrepancy emerged between the number of children in the household at different waves, the maximum number was used. However, for nearly $85 \%$ of the cases, the number of children in the household was identical at different waves or differed by only one.

Agency and parent actions postreferral included information reported by the child welfare worker regarding time to reunification from out-of-home care and whether the child experienced a subsequent reentry into out-of-home care after they were reunified.

The reporting of results analyses begins the bivariate descriptive analysis of children ages 5 through 12 in the overall NSCAW sample who entered out-of-home care and were reunified compared to those who were not reunified. The number of unweighted cases, weighted percentage and $p$-values are presented to identify significant differences between the two groups. We then provide bivariate descriptive information, specifically the number of unweighted cases and the corresponding weighted percentage, to compare reunified children who subsequently reentered out-of-home care to children who remained in their reunified inhome placement without a subsequent reentry within the 36-month study timeframe. 
In preparation for multivariate analyses and to test bivariate significance, Cox proportional hazard models were used to estimate the bivariate relationship between risk of reentry into out-of-home care and each child and family risk factor and subsequent agency and parental action postreferral. Although bivariate descriptive statistics are reported comparing reunified children who did and did not have a subsequent reentry, significance testing of the bivariate relationship with each of the study factors is evaluated using Cox analysis. Bivariate Cox models were used since those variables that showed a significant relationship indicated the need to include a specific risk factor or postreferral action in the subsequent multivariate Cox proportional hazard model. The multivariate Cox proportional hazards model estimated the relative risk of reentry within 36 months for children with several different characteristics and risk factors. Factors included in the multivariate model were identified through significance tests of the bivariate analyses as well as critical theoretical factors identified by the previous research reviewed above. Since the sample is the result of a complex multilevel sampling design, all analyses were implemented using software that is designed for analyses of clustered survey data.

Cox regression models test the relationship between child, family, and agency characteristics, and actions and the probability of reentry. These models calculated a hazard ratio (HR) for each parameter entered into the model. The HR estimated the comparative likelihood of reentry for children with different characteristics. For example, using the bivariate Cox analysis results for special education services measured at the time of the baseline assessment, a HR equal to .57 for not receiving special education services meant that the hazard for reentry into out-of-home care by the 36-month mark for children who did not receive special education services was $43 \%$ less than the hazard of reentry for children who received special education services (i.e., the reference group for this variable). The inclusion of covariates in the multivariate model calculated the HR while controlling for the relationship of other child and family characteristics to reunification.

\section{Results}

Of the 1927 children ages 5 through 12 in the NSCAW sample, $273(8.22 \%)$ were reunified with a parent or relative after an out-of-home placement. Table 1 provides descriptive statistics comparing those children who did and did not reunify by 36-months. Reunified children significantly different from children who do not reunify in regard to primary type of maltreatment $(p<.05)$, prior child welfare involvement $(p<.05)$, and family risk $(p<.001)$. Children who were reunified were more likely to have experienced physical abuse and less likely to have sexual abuse identified as their primary type of maltreatment compared to those children who were not reunified. Additionally, children who were reunified were more likely to have had prior child welfare involvement than those who were not reunified. Lastly, children who were reunified had an average family risk score that was higher than those children who did not reunify.

The 273 children who were reunified constitute the study sample, which was used for all subsequent analyses throughout the study. Substantially more than half $(60.33 \%)$ of the reunified children in the sample were male, while $39.67 \%$ were female. White/nonHispanic children comprised the largest racial/ethnic group with $42.32 \%$ of the sample, while $36.37 \%$ were Black/nonHispanic, $16.37 \%$ were Hispanic, and $4.95 \%$ were identified as other racial group. The average age in months was 105.88 ( $\mathrm{SE}=4.62)$ months. The largest percentage of child maltreatment (defined as the most serious type) was reported as neglect $(43.40 \%)$, $33.55 \%$ was reported as physical abuse, $5.29 \%$ was reported as sexual abuse, and $12.78 \%$ was reported as some other type of maltreatment as the primary type of abuse. 
Less than a quarter (22.08\%) of the children who reunified were reported by child welfare workers or caregivers as receiving special education services at the time of the baseline interview. In addition, the average CBCL score was 58.79 ( $\mathrm{SE}=1.64)$ for reunified children.

According to a baseline risk assessment, half $(50.17 \%)$ of the families of the reunified children ages 5 through 12 years had previous child welfare involvement. The mean for overall cumulative family risk was .36 with a standard error of .03 . Two-thirds $(66.66 \%)$ of children lived in households with three or more children in the home.

Given that all the children in the study sample where reunified after a period of out-of-home care, the mean time in out-of-home care prior to reunification was 12.64 (standard error of 3.52) months.

Among the 273 children reunified with a parent or relative after an out-of-home placement, $58(16.28 \%)$ subsequently reentered out-of-home care within the 36-month study period. Table 2 presents descriptive statistics for the reunified children examined in this study, that is, children in the NSCAW sample, ages 5 though 12 years, who were placed in out-of-home care and reunified with a parent or relative, by comparing those children that experienced a subsequent reentery into out-of-home care within 36 months and those that did not have a reentry.

Reunified children with a subsequent reentry were slightly older on average (113.76 months) than reunified children without a reentry (104.34 months). Racial breakdown was similar for both groups of reunified children with and without a reentry, which had the greatest percentage of children who were White/nonHispanic (49.97\% and $40.83 \%$ respectively) and fewer cases who were reported as Black/nonHispanic (25.16\% and 38.54\%), Hispanic (17.43\% and $16.16 \%)$, and other races $(7.44 \%$ and $4.46 \%)$. The majority of children were males for both reunified children with a reentry $(56.17 \%)$ and those reunified children without a reentry $(61.16 \%)$. Also, the primary type of maltreatment reported was similar for reunified children with a reentry and those without, with the largest percentages of cases reporting neglect (36.83\% and $44.67 \%$ respectively) and physical abuse $(29.10 \%$ and $34.42 \%)$. A greater percentage of reunified children in the study with a reentry received special education services (32.20\%) compared to those reunified children without a reentry (20.11\%). The mean CBCL score was higher for those reunified children with a subsequent reentry (64.57) compared to those without a subsequent reentry (57.68). A lower percentage of reunified children with a reentry had prior child welfare involvement (28.42\%) than those children without a reentry $(54.40 \%)$. The average family risk score was similar for reunified children with (0.38) and without (0.35) a subsequent reentry. The majority of reunified children for both those with a reentry (54.07\%) and those without a reentry $(69.10 \%)$ had lived in a home with three or more children living in the household while they were inhome. Additionally, reunified children with a subsequent reentry had a lower average time to reunification (7.47 months) compared to those without a reentry (13.65 months). Lastly, among the reunified children with a reentry into out-of-home care, the mean time to reentry was $6.91(\mathrm{SE}=1.50)$ months after reunification.

The Cox bivariate relationship and significance of time to reentry into out-of-home care and each child-specific, familial, and agency or parent postreferral factor are presented in Table 3 . Whereas most of the factors were found not significantly related to the hazard of reentry into out-of-home care, CBCL $(p<.05)$, prior child welfare involvement $(p<.05)$, and number of children in the household while the child was in-home $(p<.05)$ were statistically significantly related to reentry by 36 months. Specifically, the child's CBCL score at baseline was a significant $(p<.05)$ bivariate predictor of reentry with a HR of 1.05 , indicating that for each one-unit increase of the CBCL score, the hazard for reentry into out-of-home 
care increased by $5 \%$. In addition, the absence of prior child welfare involvement was also found to be significantly $(p<.05)$ related to reentry by 36 months. Children without a prior history of child welfare involvement $(\mathrm{HR}=2.20)$ or with unknown child welfare history (H.R.=6.20) had a hazard of reentry that was more than twice and more than six times respectively than the hazard of children with prior involvement with child welfare services. Also, the number of children in the household while the child was living at home was significantly $(p<.001)$ related to reentry by 36 months. Having three or more children in the household when the child is living at home $(\mathrm{HR}=0.93)$ had a hazard of reentry that was $7 \%$ less than that of children who lived in households with 2 or fewer children; however, children with an unknown number of other children in the household $(H R=4.64)$ had over four times the hazard of children from households of two or fewer children.

The results of the multivariate Cox proportional hazard model are presented in Table 4. Factors that were included in the multivariate model included those that were significant in the bivariate Cox analysis (i.e., CBCL scores, prior child welfare involvement, and number of children in the household) as well as factors of theoretical interest (i.e., age, gender, race/ ethnicity, receipt of special education services, overall family risk, and time to reunification) despite their lack of significance. The primary type of maltreatment was omitted from the final multivariate model because of the lack of theoretical support and lack of significant in the Cox bivariate analysis. A total of 257 cases of the 273 reunified children in study sample were retained in the final model, where 53 of these cases experienced a subsequent reentry. The few cases that were excluded from the final model were listwise deleted due to missing data on the continuous CBCL and family risk measures.

When controlling for all other variables, CBCL $(p<.01)$ and number of children in the household $(p<.05)$ were shown as significant factors predicting reentry by 36-months. When controlling for other factors, the CBCL had a HR of 1.06, indicating that for each one-unit increase in CBCL scores, the hazard for reentry into out-of-home care increased by about $6 \%$. Additionally, when controlling for all other factors, children living in household with three or more children has a HR of 1.23, indicating that children in households with larger number of children had a hazard for reentry that was $23 \%$ more than that of children from households of two or fewer children. For children where information regarding number of children in the household was not available, the HR was 4.26, meaning these children had a hazard for reentry that was more than four times greater than the hazard for children with two or fewer children in the household.

\section{Discussion}

Although prior research has clearly shown that reunification and reentry characteristics vary by age group, these studies focused on children who entered care between the ages of 5 and 12 , and cannot necessarily be generalized to other age groups. When controlling for other factors, two factors significantly differ for reunified children with a higher likelihood of reentry, specifically these children tend to have higher problem behavior scores as measured by the CBCL, and they are likely to have three or more children in the household while the child is living at home postreunification.

To better understand how reunified children may differ in regard to factors contributing to subsequent reentry into out-of-home care, an analysis was needed to first compare different ces between those children who are reunified and those who are not reunified. Children ages 5 through 12 who were reunified differed significantly from those children that did not reunify in regard to the primary type of abuse, whether they had prior child welfare involvement, and their overall cumulative family risk. One of the most surprising differences is that a greater percentage of children, about half $(50.17 \%)$ of those who 
reunified had prior child welfare involvement as opposed to only one-quarter $(24.77 \%)$ of those who were not reunified who had prior child welfare involvement. Additionally, reunified children on average had more family risks $(0.36)$ than children who did not reunify (0.26). Together, these findings suggest that child welfare services are not only endeavoring to reunify less challenging children in this age group. These are children with long involvement with CWS and many family problems. The authors are left to surmise that less risky children may not being reunified because they are on the path to guardianship or adoption.

The bivariate analysis of factors associated with reentry offer important information that can shape our understanding of child and family characteristics associated with reentry. Two of three factors that were significantly related to subsequent reentry as a result of the bivariate analysis are having no or unknown prior child welfare involvement and having a higher CBCL score at baseline. The third factor significantly related to reentry was the number of children in the household while the children were living in-home. While the bivariate analysis shows that having an unknown number of children in the household or reporting two or fewer children in the household has great likelihood of reentry, this finding is revised once other factors are controlled in the multivariate model.

The multivariate analysis indicated that only two of the significant bivariate factors were associated with a higher likelihood of reentry. Specifically, greater levels of problem behaviors, as reported by parents on the CBCL, indicated a higher likelihood of reentry into out-of-home care. Furthermore, children who lived in households with three or more children while the child was living at home or children who lived in household with an unknown number of children in the household were more likely to have a subsequent reentry into out-of-home care compared to those children in household with two or fewer children. Although this multivariate finding is counter to the bivariate finding, when controlling for other factors the analysis suggests that having more children in the household contributes to a higher likelihood of reentry.

These findings are not definitive, because of the inclusion of cases with missing information about household size - when the analysis is run without these cases, the sample and power drop and the coefficient are in the same direction but not significant. The increased number of missing cases in the reentry group may be an artifact of these cases being ones in which the child began their participation in the study while already in foster care. When children were at home, at baseline, the information on the number of children in the household was better. So, only when the initial placement setting of children is controlled for does the finding of a large number of children in the home suggest a strong association to reentry.

The importance of this finding on number of children in the home adds to a small but growing body of work that suggests what common sense-but not policy or practice guidelines-might predict. An earlier study looking at infants placed into foster care showed that the number of births to a parent was a strong predictor of the likelihood of a placement of an infant into foster care (Needell \& Barth, 1998). Other findings have extended this finding to older children. As discussed above, the number of behavior problems that a child has is linearly related to their likelihood of disruption-even when they have all the supports involved in an excellent treatment foster care program. There was also a trend for increased risk of disruption when the number of children in the home increased (Chamberlain et al., 2006). Although both the Chamberlain sample and this sample lacked the power to formally test for an interaction between behavior problems and number of children in the family, this is a very plausible possibility (personal communication, Patricia Chamberlain, January 28 , 2005). 
Reentry of children into care has generally been thought to be contingent on helping abusive or incapable parents to step up to the requirements of their responsibilities by better managing their substance abuse or interpersonal violence or mental health problems or using less assaultive parenting with the child who is the indicated case. The findings of this study that the preponderance of families has household with 3 or more children, often with behavior problems, offer a different perspective.

This view calls for more support regarding after school care, parent training that accounts for sibling interactions, family therapy, and, perhaps, mentoring and respite care. These families might be successful users of programs like shared family care (Barth, 1992; Price \& Simmel, 2005) or the Contact Family Program (Barth, 1990) that involve the extensive support of whole families to a reunifying family. At least at this point, the number of children in the household should become a standard demographic descriptor for understanding such caseload dynamics as placement decisions, disproportionality, and reentry dynamics.

The current study has some significant limitations. The greatest challenge in studying reentry is that reentry requires prior "selection" into the reunification group. If certain child or family characteristics make it highly unlikely that children will be reunified, then these will not appear to be related to reentry, because they are not present in an unbiased way in the reunified population. For example, in prior analyses looking at the reunification of 6 to 10 year-olds in the NSCAW sample during 18 months (Wildfire, Barth, \& Green, in press), children initially placed in a nonkinship placement were found are almost five times more likely to be reunify than children initially placed with kin. Further, children with a borderline or clinical CBCL score and children ages 6 to 10 years whose caregiver were active substance users were significantly less likely to return home. To inform this question, we tested for differences between the reunification and nonreunification groups and found that children who were reunified were similar to the other children on most dimensions and that on those few that were different, the reunified children tended to be from more troubled families.

In the multivariate models, by controlling for time in out-of-home care and time to reunification, we controlled for the speed of reunification but not for the status or reunification. That is, our analysis did not control for the likelihood that certain children are more or less likely to be reunified.

Furthermore, measures of family risk were only captured at baseline and not at the point of reunification. It is certainly plausible that family risk should change between the time of entry into the study and when children were reunified - reducing such risks is an intent of child welfare services receipt, certainly. This would reduce the accuracy of the prediction models.

As such, the appropriate interpretation of these findings is that factors are significantly related to reentry, or not, among those cases that are reunified. These should not be interpreted as general risk factors for problems in parenting or child maltreatment. These factors that are associated with reentry should not be interpreted, either, as indicators that a child should not be reunified. If that misinterpretation became widespread, then it is likely that too few children would experience a chance for reunification.

More and better measures are always desirable during the data analysis phase of research, but three improved measures stand out as key to better prediction. Including better measures of family size may be critical to explain the reentry of cases. Maternal cognitive style, cognitive limitations, and parenting schemas (Azar, Nix, \& Makin-Byrd, 2005; Benjet, Azar, \& Kuersten-Hogan, 2003) are other factors that are likely to be related to successful 
negotiation of child welfare services, but not measured here. Finally, direct observation of parents in action almost certainly has no equal in explaining child and family outcomes and was sorely missing from the measures. The study also has imprecise measures of some factors. For example, we could not, as Fuller did, obtain a precise indication of the number of children in the home before and after reunification. Our estimate of the children in the household was taken at fixed points in time (baseline or 18-months) and not during the precise time of reunification.

However, this study avoids problems related to heterogeneity of age groups and has a larger number of cases that experienced a reentry than any prior reentry study, with the exception of those that used large administrative data sets. Although measurement could have been improved, measures were obtained from child welfare workers, caregivers, and from independent assessors of child development and behavior. This is nearly unique to this study and offers findings that provide new insight to the decades long pursuit of greater understanding about what happens when children who have been reunified do not remain so.

\section{Acknowledgments}

Support for this research was provided by the Child and Adolescent Intervention Research Network (R24 MH067377) and Pathways Home (P20 DA17592.

\section{References}

Appleyard K, Egeland B, van Dulmen MHM, Sroufe LA. When more is not better: The role of cumulative risk in child behavior outcomes. Journal of Child Psychology and Psychiatry. 2005; 46(3):235-245. [PubMed: 15755300]

Azar ST, Nix RL, Makin-Byrd KN. Parenting schemas and the process of change. Journal of Marital and Family Therapy. 2005; 31:45-58. [PubMed: 15739966]

Barth, RP.; Price, A. Shared family care: Evidence from implementing an innovative child protection and family preservation program.. In: Scott, J.; Ward, H., editors. Promoting the wellbeing of vulnerable children. Jessica Kingsley Publishers; London: 2005. p. 197-227.

Barth RP, Wildfire J, Green RL. Placement into foster care and the interplay of urbanicity, child behavior problems, and poverty. American Journal of Orthopsychiatry. 2006; 76:358-366. [PubMed: 16981814]

Benjet C, Azar ST, Kuersten-Hogan R. Evaluating the parental fitness of psychiatrically diagnosed individuals: Advocating a functional-contextual analysis of parenting. Journal of Family Psychology. 2003; 17:238-251. [PubMed: 12828020]

Berrick, J.; Needell, B.; Barth, RP.; Jonson-Reid, M. The tender years: Toward developmentally sensitive child welfare services. Oxford; New York: 1998.

Chamberlain P, Price JM, Reid JB, Landsverk J, Fisher PA, Stoolmiller M. Who disrupts from placement in foster and kinship care? Child Abuse \& Neglect. 2006; 30:409-424. [PubMed: 16600372]

Courtney ME. Reentry to foster-care of children returned to their families. Social Service Review. 1995; 69:226-241.

English DJ, Edleson JL, Herrick ME. Domestic violence in one state's child protective caseload: A study of differential case dispositions and outcomes. Children and Youth Services Review. 2005; 27:1183-1201.

Festinger T. Going home and returning to foster care. Children and Youth Services Review. 1996; 18:383-402.

Fisher PA, Burraston B, Pears K. The early intervention Foster Care Program: Permanent placement outcomes from a randomized trial. Child Maltreatment. 2005; 10(1):61-71. [PubMed: 15611327]

Frame L, Berrick JD, Brodowski ML. Understanding reentry to out-of-home care for reunified infants. Child Welfare. 2000; 79:339-369. [PubMed: 10925764] 
Fuller TL. Child safety at reunification: A case-control study of maltreatment recurrence following return home from substitute care. Children and Youth Services Review. 2005; 27:1293-1306.

Goerge RM. The reunification process in substitute care. Social Service Review. 1990; 64:422-457.

Jonson-Reid M. Foster care and future risk of maltreatment. Children and Youth Services Review. 2003; 25:271-294.

Kohl PL, Edleson JL, English DJ, Barth RP. Domestic violence and pathways into child welfare services: Findings from the National Survey of Child and Adolescent Well-Being. Children and Youth Services Review. 2005; 27:1167-1182.

Marsh JC, Ryan JP, Choi S, Testa MF. Integrated services for families with multiple problems: Obstacles to family reunification. Children and Youth Services Review. 2006; 28:1074-1087.

McDonald T, Bryson S, Poertner J. Balancing reunification and reentry goals. Children and Youth Services Review. 2006; 28:47-58.

Miller KA, Fisher PA, Fetrow B, Jordan K. Trouble on the journey home: Reunification failures in foster care. Children and Youth Services Review. 2006; 28:260-274.

Nair P, Schuler ME, Black MM, Kettinger L, Harrington H. Cumulative environmental risk in substance abusing women: Early intervention, parenting stress, child abuse potential and child development. Child Abuse \& Negect. 2003; 27:997-1017.

Needell B, Barth RP. Infants entering foster care compared to other infants using birth status indicators. Child Abuse \& Neglect. 1998; 22:1179-1187. [PubMed: 9871781]

Simmel C, Price A. The shared Family Care Demonstration project: Challenges of implementing and evaluating a community-based project. Children and Youth Services Review. 2002; 24:455-470.

Slaght EF. Reexamining risk-factors in foster care. Children and Youth Services Review. 1993; 15:143-154.

Terling T. The efficacy of family reunification practices: Reentry rates and correlates of reentry for abused and neglected children reunited with their families. Child Abuse \& Neglect. 1999; 23:1359-1370. [PubMed: 10626617]

U.S. Department of Health and Human Services. Backgrounds Paper: Child and Family Services Reviews National Standards. 2001. Retrieved from http://www.acf.hhs.gov/programs/cb/monitoring/legislation/background.htm

Foster care FY1999-FY2003 entries, exits, and numbers of children in care on the last day of each federal fiscal year. 2005. From http://www.acf.hhs.gov/programs/cb/dis/tables/entryexit2002.htm

Wells K, Guo SY. Reunification and reentry of foster children. Children and Youth Services Review. 1999; 21:273-294.

Wildfire, J.; Barth, RP.; Green, RL. Reunification of children at 18-months.. In: Haskins, R.; Wulczyn, FH.; Webb, M., editors. Using research to improve practice for childen in child protective services. Brookings; Washington, DC: 2007.

Wulczyn F. Family reunification. Future of Children. 2004; 14(1):95-113.

Wulczyn, F.; Barth, RP.; Yuan, YY.; Jones Harden, B.; Landsverk, J. Beyond common sense: Evidence for child welfare policy reform. Transaction De Gruyter; New York: 2005.

Wulczyn, F.; Brunner, K.; Goerge, R. Center for Children at the University of Chicago; Chapin Hall: 1999. An update from the multistate foster care data archive foster care dynamics 1983-1997.. 


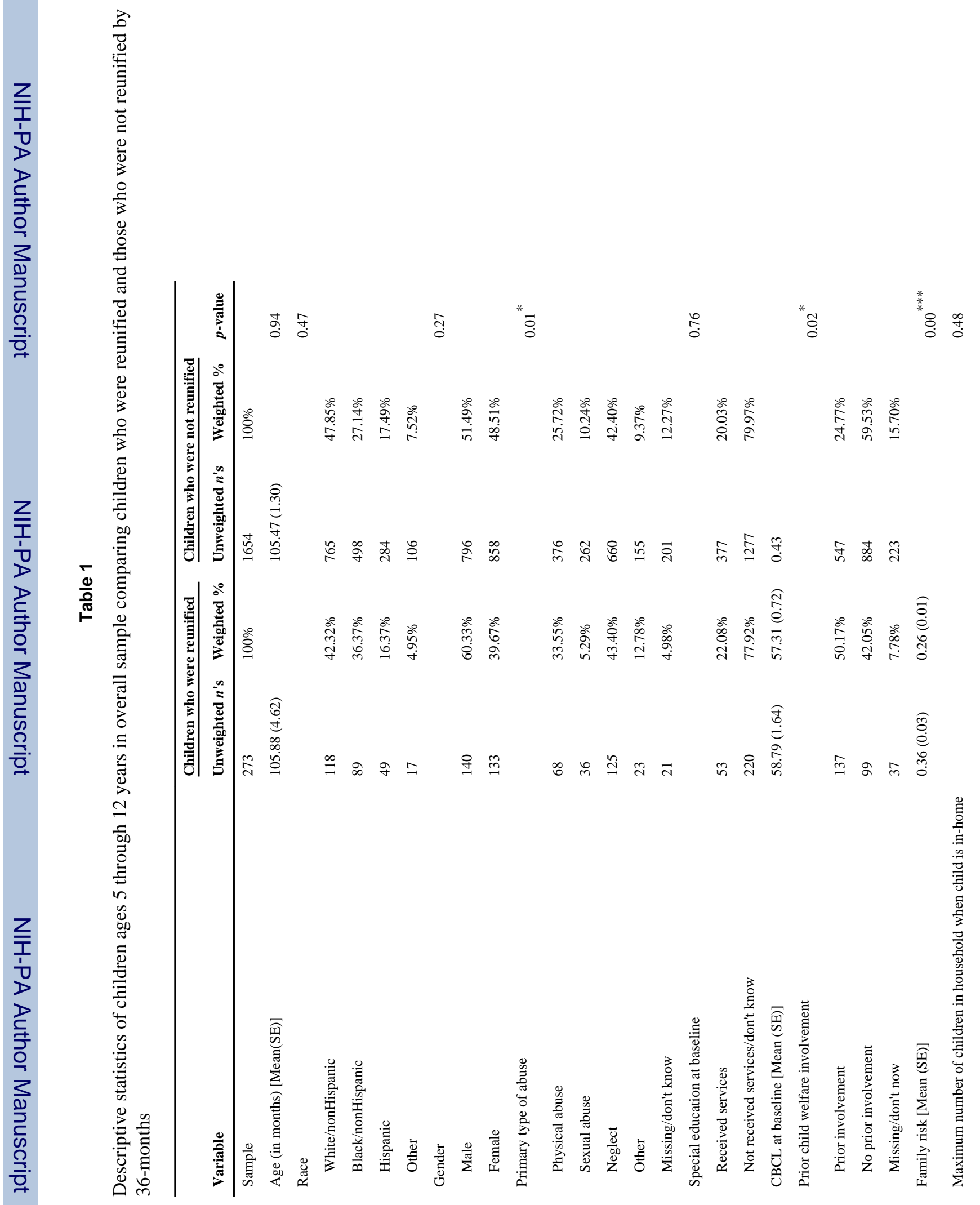




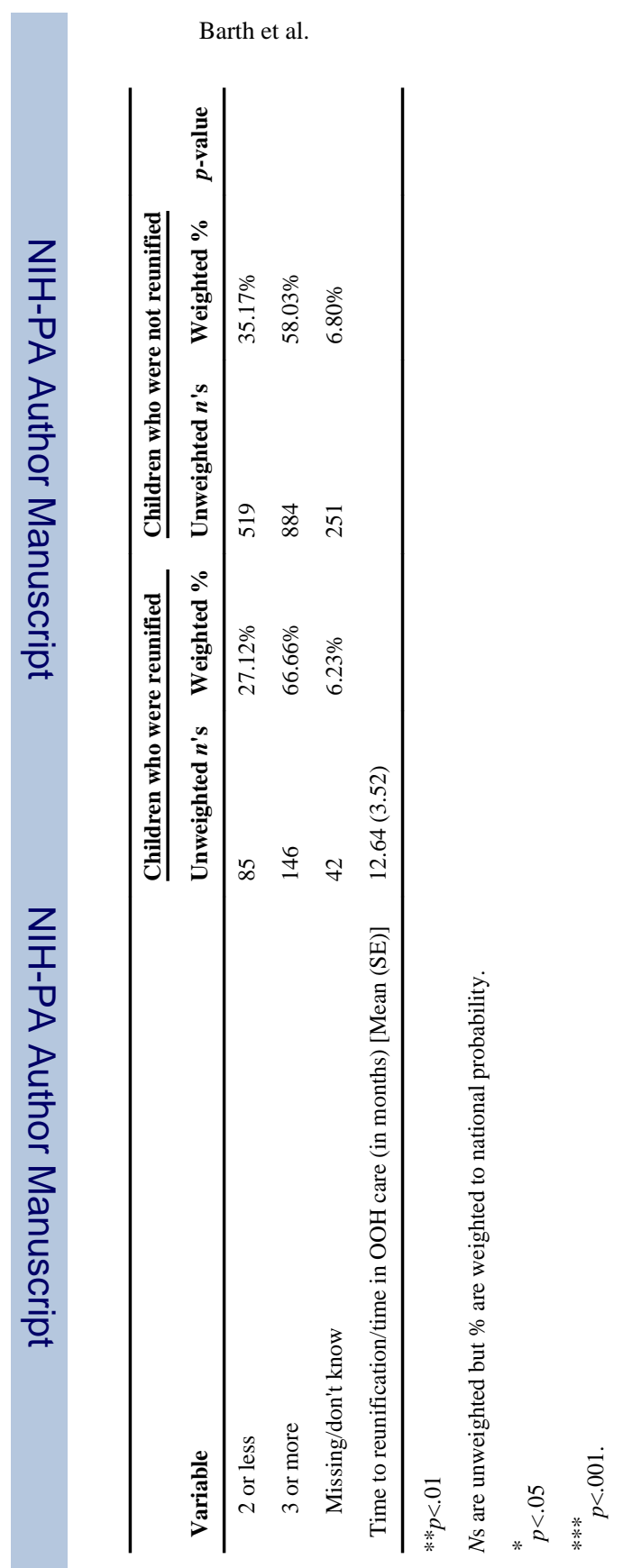

Page 14 
Table 2

Descriptive statistics of children ages 5 through 12 years in study sample of reunified children as related to subsequent reentry into out-of-home care $(\mathrm{OOHC})$

\begin{tabular}{|c|c|c|c|c|}
\hline \multirow[b]{2}{*}{ Variable } & \multicolumn{2}{|c|}{$\begin{array}{l}\text { Reunified children with a subsequent reentry } \\
\text { into } \mathrm{OOH} \text { care } \\
\end{array}$} & \multicolumn{2}{|c|}{$\begin{array}{l}\text { Reunified children without a subsequent } \\
\text { reentry into } \mathrm{OOH} \text { care }\end{array}$} \\
\hline & Unweighted $n$ 's & Weighted \% & Unweighted $n$ 's & Weighted \% \\
\hline Sample & 58 & $100.00 \%$ & 215 & $100.00 \%$ \\
\hline Age (in months) [Mean(SE)] & $113.76(6.13)$ & & $104.34(5.01)$ & \\
\hline \multicolumn{5}{|l|}{ Race } \\
\hline White/nonHispanic & 23 & $49.97 \%$ & 95 & $40.83 \%$ \\
\hline Black/nonHispanic & 16 & $25.16 \%$ & 73 & $38.54 \%$ \\
\hline Hispanic & 14 & $17.43 \%$ & 35 & $16.16 \%$ \\
\hline Other & 5 & $7.44 \%$ & 12 & $4.46 \%$ \\
\hline \multicolumn{5}{|l|}{ Gender } \\
\hline Male & 29 & $56.17 \%$ & 111 & $61.16 \%$ \\
\hline Female & 29 & $43.83 \%$ & 104 & $38.86 \%$ \\
\hline \multicolumn{5}{|l|}{ Primary type of abuse } \\
\hline Physical abuse & 17 & $29.10 \%$ & 51 & $34.42 \%$ \\
\hline Sexual abuse & 7 & $5.84 \%$ & 29 & $5.19 \%$ \\
\hline Neglect & 22 & $36.83 \%$ & 103 & $44.67 \%$ \\
\hline Other & 7 & $23.78 \%$ & 16 & $10.64 \%$ \\
\hline Missing/don't know & 5 & $4.46 \%$ & 16 & $5.08 \%$ \\
\hline \multicolumn{5}{|l|}{ Special education at baseline } \\
\hline Received services & 12 & $32.20 \%$ & 41 & $20.11 \%$ \\
\hline Not received services/don't know & 46 & $67.80 \%$ & 174 & $79.89 \%$ \\
\hline $\mathrm{CBCL}$ at baseline [Mean (SE)] & $64.57(2.16)$ & & $57.68(1.85)$ & \\
\hline \multicolumn{5}{|l|}{ Prior child welfare involvement } \\
\hline Prior involvement & 27 & $28.42 \%$ & 110 & $54.40 \%$ \\
\hline No prior involvement & 20 & $49.71 \%$ & 79 & $40.56 \%$ \\
\hline Missing/don't now & 11 & $21.88 \%$ & 26 & $5.04 \%$ \\
\hline Family risk [Mean (SE)] & $0.38(0.05)$ & & $0.35(0.03)$ & \\
\hline \multicolumn{5}{|l|}{$\begin{array}{l}\text { Maximum number of children in } \\
\text { household when child is in-home }\end{array}$} \\
\hline 2 or less & 16 & $24.26 \%$ & 69 & $27.67 \%$ \\
\hline 3 or more & 23 & $54.07 \%$ & 123 & $69.10 \%$ \\
\hline Missing/don't know & 19 & $21.67 \%$ & 23 & $3.23 \%$ \\
\hline $\begin{array}{l}\text { Time to reunification/time in } \mathrm{OOH} \text { care (in } \\
\text { months) [Mean (SE)] }\end{array}$ & $7.47(2.14)$ & & $13.65(4.21)$ & \\
\hline \multicolumn{5}{|l|}{ Reentry } \\
\hline Reentry in $\mathrm{OOH}$ care & 58 & $100.00 \%$ & 0 & $0.00 \%$ \\
\hline No reentry into $\mathrm{OOH}$ care & 0 & $0.00 \%$ & 215 & $100.00 \%$ \\
\hline Time to reentry (in months) [Mean(SE)] & $6.91(1.50)$ & & & \\
\hline \multicolumn{5}{|l|}{ Time to reentry (in months) } \\
\hline $0-2$ & 14 & $28.47 \%$ & & \\
\hline
\end{tabular}




\begin{tabular}{|c|c|c|c|c|}
\hline \multirow[b]{2}{*}{ Variable } & \multicolumn{2}{|c|}{$\begin{array}{l}\text { Reunified children with a subsequent reentry } \\
\text { into } \mathrm{OOH} \text { care } \\
\end{array}$} & \multicolumn{2}{|c|}{$\begin{array}{l}\text { Reunified children without a subsequent } \\
\text { reentry into OOH care }\end{array}$} \\
\hline & Unweighted $n$ 's & Weighted \% & Unweighted $n$ 's & Weighted \% \\
\hline $3-5$ & 17 & $27.27 \%$ & & \\
\hline $6-11$ & 10 & $25.62 \%$ & & \\
\hline $12-17$ & 10 & $8.85 \%$ & & \\
\hline $18-23$ & 4 & $6.17 \%$ & & \\
\hline $24-29$ & 2 & $0.76 \%$ & & \\
\hline $30-35$ & 1 & $2.86 \%$ & & \\
\hline
\end{tabular}

$N$ s are unweighted but $\%$ are weighted to national probability. 


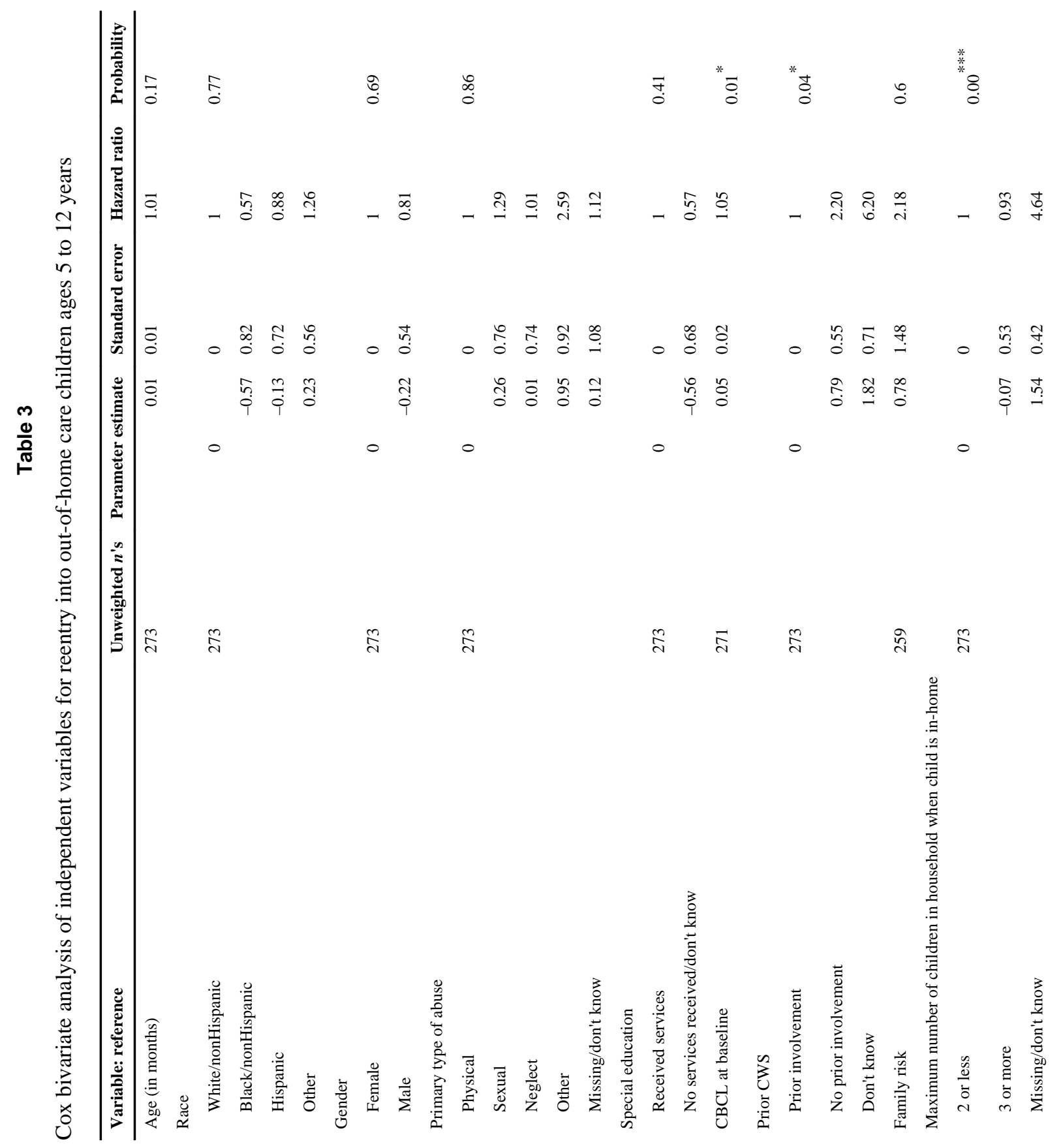

Child Youth Serv Rev. Author manuscript; available in PMC 2011 July 13. 


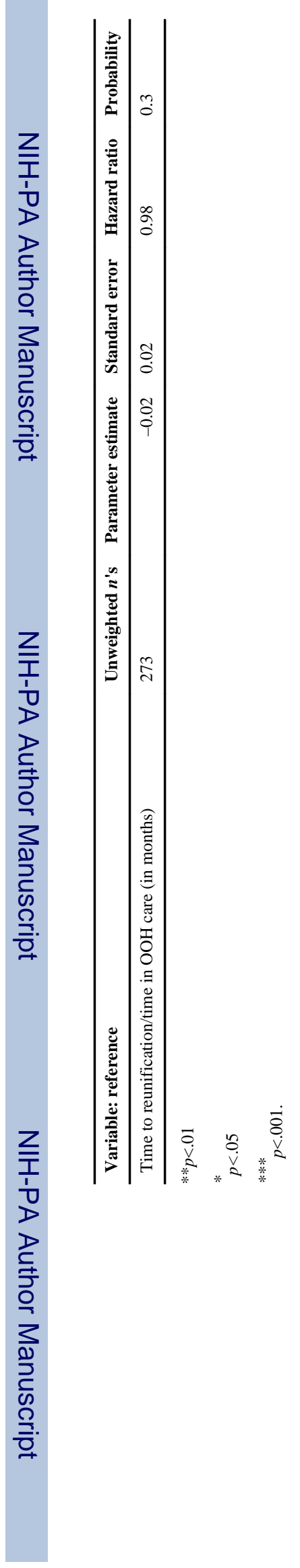


Table 4

Hazard ratio and significance of Cox multivariate regression for reentry into out-of-homecare for ages 5-12

\begin{tabular}{|c|c|c|}
\hline Unweighted $n$ 's & & 257 \\
\hline Number of cases with reentry into $\mathrm{OOH}$ care & & 53 \\
\hline Variable & Hazard ratio & $p$-value \\
\hline Age (in months) & 1.00 & 0.65 \\
\hline \multicolumn{3}{|l|}{ Race } \\
\hline White/nonHispanic & 1 & 0.90 \\
\hline Black/nonHispanic & 0.74 & \\
\hline Hispanic & 0.75 & \\
\hline Other & 0.54 & \\
\hline \multicolumn{3}{|l|}{ Gender } \\
\hline Female & 1 & 0.51 \\
\hline Male & 0.68 & \\
\hline \multicolumn{3}{|l|}{ Special education } \\
\hline Received services & 1 & 0.98 \\
\hline No services received/Don't know & 0.98 & \\
\hline $\mathrm{CBCL}$ at baseline & 1.06 & $0.01^{*}$ \\
\hline \multicolumn{3}{|l|}{ Prior child welfare involvement } \\
\hline Prior involvement & 1 & 0.09 \\
\hline No prior involvement & 2.47 & \\
\hline Missing/don't know & 7.09 & \\
\hline Family risk & 0.82 & 0.90 \\
\hline \multicolumn{3}{|c|}{ Maximum number of children in household when child is in-home } \\
\hline 2 or less & 1 & $0.03^{*}$ \\
\hline 3 or more & 1.23 & \\
\hline Missing/don't know & 4.26 & \\
\hline Time to reunification/time in $\mathrm{OOH}$ care (in months) & 0.94 & 0.10 \\
\hline \multicolumn{3}{|l|}{$* * p<.01$} \\
\hline$* * * p<.001$ & & \\
\hline$p<.05$ & & \\
\hline
\end{tabular}

